\title{
Randomized controlled clinical study assessing two membranes for guided bone regeneration of peri-implant bone defects: 3-year results
}

Basler, Tobias ; Naenni, Nadja ; Schneider, David ; Hämmerle, Christoph H F ; Jung, Ronald E ; Thoma, Daniel S

\begin{abstract}
OBJECTIVES To assess two- and three-dimensional changes of the peri-implant tissues as well as clinical, biological, and radiological outcomes of implants having been treated with resorbable or nonresorbable membranes at 3 years. MATERIALS AND METHODS Twenty-three patients were re-examined after having received a single-tooth implant in the esthetic zone in conjunction with guided bone regeneration (GBR) using either a resorbable (RES) or a titanium-reinforced nonresorbable membrane (N-RES) and demineralized bovine bone mineral. Volumetric and linear as well as clinical and radiographic measurements were performed at crown insertion (baseline), at 1 year (FU-1) and 3 years (FU-3). Statistics were performed by means of parametric and nonparametric tests. RESULTS Minor, but ongoing buccal volume loss was observed in both groups during the 3-year follow-up. A slightly higher volume loss was observed in group RES (-0.22 mm) compared to NRES $(-0.14 \mathrm{~mm})$ at 1 year (FU-1), but aligned at 3 years (FU-3) RES $(-0.30 \mathrm{~mm}) \mathrm{N}-\mathrm{RES}(-0.32 \mathrm{~mm})$. All changes over time were statistically significantly different within $(\mathrm{p}<.05)$, but not between the groups $(\mathrm{p}>.05)$. Stable median interproximal bone levels after 3 years (FU-3); $0.26 \mathrm{~mm}(0.04 ; 0.36)$ (RES) and $0.14 \mathrm{~mm}(0.08 ; 0.20)$ (N-RES) and healthy tissues (BOP, PD) were obtained with both membranes. CONCLUSIONS Both treatment modalities resulted in minor, but ongoing contour changes of the peri-implant tissues. Stable interproximal bone levels and healthy tissues can be obtained with membranes up to 3 years.
\end{abstract}

DOI: https://doi.org/10.1111/clr.13147

Posted at the Zurich Open Repository and Archive, University of Zurich

ZORA URL: https://doi.org/10.5167/uzh-152294

Journal Article

Accepted Version

Originally published at:

Basler, Tobias; Naenni, Nadja; Schneider, David; Hämmerle, Christoph H F; Jung, Ronald E; Thoma, Daniel S (2018). Randomized controlled clinical study assessing two membranes for guided bone regeneration of periimplant bone defects: 3-year results. Clinical Oral Implants Research, 29(5):499-507.

DOI: https://doi.org/10.1111/clr.13147 


\title{
Randomized controlled clinical study assessing two membranes for guided bone regeneration of peri-implant bone defects: 3-year results
}

\author{
Tobias Basler $^{1} *$, Nadja Naenni ${ }^{1 *}$, David Schneider ${ }^{1}$, Christoph H.F. \\ Hämmerle ${ }^{1}$, Ronald E. Jung ${ }^{1}$, Daniel S. Thoma ${ }^{1}$ \\ * these authors contributed equally
}

Key words: alveolar ridge augmentation, membranes, volume stability, volumetric analysis, dental implants

Running title: guided bone regeneration using two different membranes:

3-year results

Number of figures: 2

Number of tables: 3

Address for correspondence: PD Dr. Daniel S. Thoma

Clinic of Fixed and Removable Prosthodontics and

Dental Material Science

Center of Dental Medicine, University of Zurich

Plattenstrasse 11

$\mathrm{CH}-8032$ Zurich, Switzerland

Phone: +41446343250

Fax: +41446344305

e-mail: daniel.thoma@zzm.uzh.ch

1 Clinic of Fixed and Removable Prosthodontics and Dental Material Science, University of Zurich, Zurich, Switzerland 


\section{Abstract}

Objectives: to assess two- and three-dimensional changes of the periimplant tissues as well as clinical, biological and radiological outcomes of implants having been treated with resorbable or non-resorbable membranes at 3 years.

\section{Materials and methods:}

Twenty-three patients were reexamined after having received a singletooth implant in the esthetic zone in conjunction with guided bone regeneration (GBR) using either a resorbable (RES) or a titaniumreinforced non-resorbable membrane (N-RES) and demineralized bovine bone mineral. Volumetric and linear as well as clinical and radiographic measurements were performed at crown insertion (baseline), at one year (FU-1) and three years (FU-3). Statistics were performed by means of parametric and non-parametric tests.

\section{Results:}

Minor, but ongoing buccal volume loss was observed in both groups during the 3-year follow-up. A slightly higher volume loss was observed in group RES $(-0.22 \mathrm{~mm})$ compared to N-RES $(-0.14 \mathrm{~mm})$ at one year $(\mathrm{FU}-1)$, but aligned at 3 years (FU-3) RES $(-0.30 \mathrm{~mm}) \mathrm{N}-\operatorname{RES}(-0.32 \mathrm{~mm})$. All changes over time were statistically significantly different within $(p<0.05)$, but not between the groups $(p>0.05)$. Stable median interproximal bone levels after 3 years (FU-3); $0.26 \mathrm{~mm}(0.04 ; 0.36)$ (RES) and $0.14 \mathrm{~mm}(0.08$; $0.20)(N-R E S)$ and healthy tissues (BOP, PD) were obtained with both membranes.

\section{Conclusions:}

Both treatment modalities resulted in minor, but ongoing contour changes of the peri-implant tissues. Stable interproximal bone levels and healthy tissues can be obtained with membranes up to 3 years. 


\section{Introduction}

Guided bone regeneration (GBR) is a frequently applied and welldocumented clinical procedure to regenerate hard tissue deficiencies in localized alveolar defects (Benic, Hammerle, 2014). GBR relies on the principle of using a barrier membrane with or without supporting bone (substitute material) (Dahlin, Linde, Gottlow, Nyman, 1988; Dahlin, Sennerby, Lekholm, Linde, Nyman, 1989; Hammerle, Bragger, Schmid, Lang, 1998). Various modifications of the original technique were evaluated as well as a plethora of materials tested (Esposito, Grusovin, Worthington, Coulthard, 2006). In terms of GBR membranes, resorbable native collagen membranes and non-resorbable expanded polytetrafluorethylen (ePTFE) membranes were most frequently used (Esposito, et al., 2009). Both types of membranes offer advantages and disadvantages based on the clinical and technical handling, the rate of complications and the expected long-term outcomes (Zitzmann, Naef, Scharer, 1997). Major advantages of ePTFE membranes include the stability of the membrane (Schneider, et al., 2014) per se and long-term successful outcomes at dehiscence-type defects. In contrast, resorbable collagen membranes offer benefits in terms of no need to remove the membrane at second stage surgery, favorable biologic attributes and similar long-term performance at dehiscence-type defects (Carpio, Loza, Lynch, Genco, 2000; Merli, et al., 2016). (Early) studies, comparing the two membranes for bone formation at implant sites revealed similar outcomes in terms of the amount of regenerated bone (Zitzmann, et al., 1997) (Carpio, et al., 2000). More recent evidence however, revealed a greater loss of horizontal thickness between implant placement with simultaneous GBR and 6 months thereafter when a resorbable membrane had been used (Naenni, et al., 2017). Scientific data is controversial whether the amount of bone on the buccal side of dental implants influences the esthetic outcomes of implants therapy (Merheb, et al., 2017; Sicilia, et al., 2015). It has even been shown that untreated dehiscence defects result in non-inferior outcomes at 1 year compared to 
GBR-treated sites (Jung, et al., 2017). From a clinical point of view, biological, radiological and volumetric stability of the peri-implant tissues are crucial. To date, scientific data on the stability of the peri-implant tissues, comparing dehiscence-type defects using the two membranes, are rare.

The aim of the present study was, therefore, to assess two- and threedimensional changes of the peri-implant tissues as well as clinical, biological and radiological outcomes of implants having been treated with resorbable or non-resorbable membranes at 3 years post insertion of the final reconstructions.

\section{Materials and methods}

The present study was designed as a follow-up study of a prospective randomized controlled clinical trial (Naenni, et al., 2017) and approved by the local ethical committee (Nr. 2010-0051/5).

Inclusion criteria

1. Periodontal healthy patients (periodontal probing depths $<4 \mathrm{~mm}$ )

2. Good oral hygiene (full mouth plaque index $<25 \%$; (O'Leary, Drake, Naylor, 1972)

3. Adequate control of inflammation (full mouth bleeding on probing $<25 \%$; (Ainamo, Bay, 1975)

4. Single-tooth gaps with a buccal alveolar bone deficiency

5. Planned implant placement $>6$ weeks after tooth extraction

6. A buccal bone defect after implant placement

Patient had to fulfill inclusion criteria prior to surgery (1-5). In case of a defect-free implant placement, exclusion could be performed after surgery (6).

\section{Surgical protocol}

Details on the surgical procedures are described in detail in an earlier publication (Naenni, et al., 2017). In brief, a full flap was prepared and a dental implant (OsseoSpeed, ASTRA TECH Implant System DENTSPLY, 
Mölndal, Sweden) placed in a prosthetically ideal position. A demineralized bovine bone mineral (DBBM, BioOss spongiosa granules, particle size 0.25-1mm; Geistlich Pharma AG, Wolhusen Switzerland) was used to augment the dehiscence-type defects. Subsequently, a resorbable collagen membrane (BioGide, Geistlich Pharma AG; RES) or a nonresorbable ePTFE-membrane (Gore-Tex, W.L. Gore \& Assoc., Flagstaff, Arizona, USA; N-RES) was randomly applied. In the RES group, membranes were cut into an overlapping shape of at least $2 \mathrm{~mm}$ and then fixed buccally by two or three resorbable polylactic acid pins (Inion Pins, Geistlich AG, Wolhusen, Switzerland). Membranes in the N-RES group were equally shaped, customized extraorally and then stabilized by nonresorbable titanium pins (Frios, Friadent $\mathrm{GmbH}$, Mannheim, Germany). Releasing incisions were made within the periosteum in order to obtain a tension-free wound closure using non-resorbabale sutures (Gore-Tex sutute; Gore, Flagstaff, AZ, USA). Seven to 10 days after surgery suture removal was performed. In case of a soft tissue dehiscence, a strict recall interval was performed and patients were advised to apply disinfecting agents (Plak Out Gel, Kerr Hawe SA, Bioggio, Switzerland and Solcoseryl, Meda Pharma GmbG, Wangen-Brüttisellen, Switzerland).

Re-entry surgery was performed at 6 months to remove the N-RES membrane and the titanium pins and to record the quality and quantity of the obtained bone in both groups (N-RES and RES). Abutment connection was performed 2 to 4 months later. All implants were restored with final reconstructions within four months and a baseline (BL) examination scheduled.

Follow-up visits

At baseline ( $\mathrm{BL})$, one year (FU-1) and $3(\mathrm{FU}-3)$ years, follow-up clinical examinations were planned for all patients.

The following parameters were assessed:

Clinical measurements 
Probing depth (PD) (Ramfjord, 1974), clinical attachment level (CAL), plaque control record (PCR) (O'Leary, et al., 1972), and bleeding on probing (BOP) (Ainamo, Bay, 1975) at six sites for all implants and the two neighboring teeth. Furthermore, at the buccal aspect of all implants, the width of the keratinized mucosa was measured. Peri-implant mucositis and peri-implantitis were defined as follows:

1. peri-implant mucositis (clinical signs of inflammation without crestal bone loss, PD $\geq 5 \mathrm{~mm}$ and $\mathrm{BOP}$ at $>50 \%$ of the sites at a given implant)

2. peri-implantitis (mucositis in conjunction with crestal bone loss $\geq 2 \mathrm{~mm}$ ) (Mombelli, Lang, 1994)

\section{Radiographic measurements}

Two-dimensional intraoral X-rays at baseline, FU-1 and FU-3 were taken using a paralleling technique with rim-holders and digital films. An opensource software (Image J, National Institutes of Health, Bethesda, Maryland USA) was used to assess interproximal marginal bone levels. A calibration was performed using the distance between implant threads as well as the known implant length and respective diameter. At the mesial and distal aspect of the implant, the distance from the reference point (implant shoulder) to the first bone-to-implant contact was measured.

\section{Linear and volumetric outcome measures}

Conventional impressions with an a-silicone material (President, Contène/Whaledent Altstätten, Switzerland) were taken at all follow-up visits and casts of dental stone class IV were poured. The casts were examined meticulously at the relevant site before they were scanned with a desktop 3D scanner (Imetric 3D SA, Courgenay, Switzerland). Accordingly, the generated stereolithographic files (standard tessellation language, STL) were imported into an image analysis software (Swissmeda Software, Swissmeda AG, Zurich, Switzerland). All STL files (baseline, FU-1, FU-3) of each patient were superimposed using a semi- 
automatic algorithm and then manually adjusted according to reference structures, mainly teeth, which had not been treated during the observation period. This step was double checked and confirmed by an additional experienced examiner not part of the study. A region of interest (ROI) was defined on the baseline STL-file. The coronal border of the ROI followed the mucosal margin of the implant site with a clearance of $1 \mathrm{~mm}$ and extended 4-5 millimeter apically remaining within the keratinized tissue. Mesio-distally, the ROI corresponded to the width of the singletooth reconstruction.

\section{Volumetric measurements}

The software then calculated the mean distance (MD) between the baseline surface and the FU-1 (MD1) surface as well as between the baseline and the FU-3 (MD3) surface. Changes between FU-1 and FU-3 were calculated by subtraction of the above-described results.

\section{Linear measurements}

A cross-section at the center of the implant crown was selected resulting in a representative contour of the buccal peri-implant tissues width (TW). Horizontal measurements were carried out at $1 \mathrm{~mm}$ (TW1) and at $3 \mathrm{~mm}$ (TW3) below the buccal mucosal margin. The differences $(\Delta)$ between the absolute ridge width at $1 \mathrm{~mm}(\Delta \mathrm{TW} 1)$ and $3 \mathrm{~mm}(\Delta \mathrm{TW} 3)$ represented the changes of the tissue thickness over time.

\section{Statistical analysis}

The primary endpoint was the change in horizontal tissue thickness at the buccal aspect of the implant. The secondary endpoints consisted of the vertical height of the interproximal bone mesial and distal of the implant; the clinical parameters (PD, $P C R, B O P)$, the soft tissue condition (thickness of the keratinized mucosa and soft tissue dehiscences). The metric variables were described with values in mean, median, standard deviation, and quartiles. The categorical measures by frequencies and 
proportions. The statistical comparisons of the group mean for the metric variables applied parametric mixed linear models since the data within a patient was dependent (clustered). For the comparison of the two groups, the nonparametric Wilcoxon-Mann-Whitney test with exact $p$-value determination was applied, due to the small sample size and the data distribution. The effects, difference of medians, were estimated by Hodges-Lehmann estimates together with its $95 \%$ confidence intervals. The significance level was set at 5\%. No correction was applied for the multiple testing since only one primary endpoint was considered. To analyze a possible confounding factor (OK/UK) nonparametric 2-way ANOVA tests was applied.

\section{Results}

Demographics

At 3 years, 23 out of 27 patients ( 11 male, 12 female; mean age 56.6 years (SD: 17.4) were re-examined. Four patients could not be recalled due to the following reasons: one patient had died, three patients had moved away. At the time of implant placement all patients had generally been healthy. During the observation period three patients had reported general medical issues (one heart attack, one osteoporosis, one fibromyalgia).

In the early healing period, five wound dehiscences were observed in the RES group and two in group N-RES. One dehiscence (N-RES) persisted until the re-entry surgery 6 months after implant placement. No membranes were removed prior to the scheduled re-entry time-point and no differences in residual defect heights could be detected in neither of the two groups. Moreover, dehiscences were not associated with an increased residual defect height (Naenni et al. 2016).

\section{Clinical measurements}

Median PD values were stable in both groups over time with minimal changes ranging between $3.17 \mathrm{~mm}$ (Q1: 2.67; Q3: 3.42) at baseline, 
$3.00 \mathrm{~mm}(2.83 ; 3.33)$ at $\mathrm{FU}-1$ and $3.17 \mathrm{~mm}(2.50 ; 4.17)$ at $\mathrm{FU}-3$ for group RES. Corresponding median values in group N-RES were $3.00 \mathrm{~mm}(2.67$; $3.67), 3.00 \mathrm{~mm}(2.83 ; 3.50)$ and $3.33 \mathrm{~mm}(3.17 ; 3.67)$. Median PD values for control teeth were smaller when compared to implant sites at all timepoints (Appendix 1). Differences between control teeth and implants were statistically significant at all time-points $(p=0.0171, p=0.0059, p=0.0068)$ (RES) and ( $p=0.0313, p=0.0195, p=0.0039)$ (N-RES). (Appendix 2).

Mean plaque indices ( $P C R$ ) were lower at implant sites in both groups at all time-points compared to the control teeth. At FU-3, no significant differences were observed comparing teeth and implant sites (RES: $\mathrm{p}=0.250 ; \mathrm{N}$-RES: $\mathrm{p}=0.063$ ).

Median BOP values were higher at implant sites (RES: $27.8 \%, 33.3 \%$, $30.3 \%$ ), (N-RES: $25.9 \%, 22.2 \%, 48.1 \%$ ) compared to natural control teeth (RES: $27.1 \%, 22.0 \%, 15.2 \%$ ), (N-RES: $12.7 \%, 8.3 \%, 20.0 \%$ ) at all time-points. At 3 years, only the comparison between implant sites in group N-RES and natural control teeth was significant $(p=0.008)$. None of the differences between the two membrane groups revealed any statistical significance $(p>0.05)$. (Appendix 1$)$

\section{Radiographic measurements}

At baseline, the radiographic assessment demonstrated median interproximal marginal bone levels (MBLinterprox) of $0.11 \mathrm{~mm}(-0.07$; $0.46)$ (RES) and $0.14 \mathrm{~mm}(0.06 ; 0.19)$ (N-RES). At FU-1, corresponding values were $0.23 \mathrm{~mm}(0.10 ; 0.41)$ (RES) and $0.13 \mathrm{~mm}(-0.02 ; 0.23)(\mathrm{N}-$ RES) At FU-3, median MBLinterprox measured $0.26 \mathrm{~mm}(0.04 ; 0.36)$ (RES) and $0.14 \mathrm{~mm}(0.08 ; 0.20)$ (N-RES group). All data are displayed in Table 1 . The differences between RES and N-RES were neither statistically significant at BL $(p=0.654), F U-1(p=0.156), F U-3(p=0.500)$ nor over time $(p=0.340 ; p=0.853)$. In addition, the percentage of implants demonstrating a MBLinterprox of $>1 \mathrm{~mm}$ was $0(0 \%)$ (RES) and $0(0 \%)$ (N-RES) at FU-3. 
Volumetric outcome measures

In general, within the first year after the insertion of the final reconstructions, a slightly higher volume loss was observed in group RES compared to group N-RES. At FU-3, this difference could no longer be observed as expressed by a similar volume change between baseline and FU-3 in both groups. The calculated median volume changes at the buccal aspect (MD1) were $-0.19 \mathrm{~mm}(-0.31 ;-0.06)(p=0.002 ;$ RES) and $-0.12 \mathrm{~mm}$ $(-0.37 ; 0.04)(p=0.1855 ; N-R E S)$ between $B L$ and $F U-1$. The respective changes between baseline and FU-3 (MD3) were $-0.31 \mathrm{~mm}(-0.45 ;-0.07)$ $(p=0.00039 ;$ RES $)$ and $-0.38 \mathrm{~mm}(-0.40 ;-0.14)(p=0.0078 ; N-R E S)$. The differences between the two groups were not statistically significant $(p=0.5923 ; p=0.6685)$. (Figure 1 , Table 2 )

\section{Linear outcome measures}

When measuring the horizontal changes at the level $1 \mathrm{~mm}$ (TW1) and $3 \mathrm{~mm}$ (TW3) below the mucosal margin, changes over time ( $\Delta \mathrm{TW})$ were minimal in both groups. Changes between baseline and FU-1 were $0.24 \mathrm{~mm}(-0.42 ;-0.13)(\Delta \mathrm{TW} 1)$ and $-0.33 \mathrm{~mm}(-0.48 ;-0.15)(\Delta \mathrm{TW} 3)$, at between baseline and FU-3 $-0.36 \mathrm{~mm}(-0.77 ;-0.09)$ and $-0.49 \mathrm{~mm}(-0.89$; $-0.22)$ in group RES. Corresponding values in group N-RES were $-0.29 \mathrm{~mm}$ $(-0.42 ;-0.13),-0.24 \mathrm{~mm}(-0.53 ;-0.17),-0.38 \mathrm{~mm}(-0.44 ;-0.31)$ and $0.60 \mathrm{~mm}(-0.84 ;-0.30)$. All changes over time were statistically significantly different within $(p<0.05)$, but not between the groups ( $p>0.05)$ (Figure 2, Table 3). 


\section{Discussion}

The present follow-up study evaluating linear and volumetric changes of the peri-implant tissues as well peri-implant health of implant sites with buccal guided bone regeneration demonstrated:

i) a minimal, but continuous decrease of the buccal contour between the insertion of the final reconstruction and 3 years,

ii) no difference for any of the outcome measures between sites treated with resorbable or non-resorbable membranes at the 3year follow-up.

iii) higher PD and BOP values around dental implants compared to natural teeth at 3 years.

Long-term outcomes focusing not only on implant survival, but also on the success of dental implants have been the focus of intensive research lately (Hjalmarsson, Gheisarifar, Jemt, 2016). Recently published systematic reviews have focused both on the stability of augmented sites (Merli, et al., 2016) and esthetic outcomes (Chen, Buser, 2014). Although basic mechanisms of remodeling at extraction sites and at dental implants seem to be understood (Chen, Beagle, Jensen, Chiapasco, Darby, 2009); there is still a lack of information on the stability of the buccal contour following GBR procedures.

Stability and changes thereof are both dependent on the underlying hard and soft tissues. According to current literature, the average bone thickness after GBR at the cervical aspect of dental implant measures approximately $1.56 \mathrm{~mm}$ (Miyamoto, Obama, 2011) and increases to $2.2 \mathrm{~mm}$ in the middle section (Buser, et al., 2013; Miyamoto, Obama, 2011). Over time, remodeling processes influence these dimensions and areas without radiologically detectable bone at the buccal aspect of the implant are no exception (Benic, et al., 2012; Kuchler, Chappuis, Gruber, Lang, Salvi, 2016; Miyamoto, Obama, 2011). Surprisingly, these findings are only associated with recessions $\leq 1 \mathrm{~mm}$ of the buccal soft tissues. Thin bone wall phenotypes $(<1 \mathrm{~mm})$ tend to show a more progressive 
resorption pattern, whereas the facial soft tissue thickness seems not correlate with the bone wall dimension underneath (Chappuis, Araujo, Buser, 2017). Soft tissue grafting procedures for volume gain might compensate for ongoing changes of the hard tissues, but scientific evidence is missing.

With the recently developed, non-invasive technique to evaluate volumetric changes, (De Bruyckere, Eghbali, Younes, De Bruyn, Cosyn, 2015; Sanz Martin, Benic, Hammerle, Thoma, 2016; Schneider, Grunder, Ender, Hammerle, Jung, 2011) even small changes can be detected. This accurate and adequate procedure proved to be successful and precise in analyzing volumetric changes of tissues over time based on various preclinical and clinical studies (Bienz, et al., 2017; Schneider, et al., 2011; Thoma, et al., 2010)

Even though, the dimensional changes in the present study are small (less than $0.4 \mathrm{~mm}$ in both groups), a possible continuity of ongoing volume changes might cause esthetic problems in the future. The findings of the present study demonstrating a loss of the buccal contour up to 3 years post loading are not in line with a recently published study (Buser, et al., 2013). In that particular clinical study, stable volumes of the buccal contour were found. In contrast to the present study, longer-term outcomes were evaluated by using CBCTs or esthetic scores. One has to bear in mind, however, that these scores are subjectively assessed using a grading system and report no absolute values. In general, the most frequently used parameters for the assessment of peri-implant mucosal esthetics are the vertical position of the buccal mucosal margin and the height of the interproximal papillae (Benic, et al., 2012). A drawback of this assessment method is the fact that these parameters do not take the buccal contour into account.

According to a recently published systematic review (Lutz, Neukam, Simion, Schmitt, 2015), more longer-term studies were demanded with a focus on three-dimensional changes of the buccal tissues using noninvasive methods, since smaller changes might not be detected by the 
naked eye. In a 5-year follow-up of 33 patients, volumetric and linear changes of the peri-implant tissues were evaluated (Sapata, et al.). One of the most important outcomes, assessed in that study, was the comparison of contour changes between implant sites and natural control teeth. Up to the 1-year follow-up, natural control teeth lost $0.08 \mathrm{~mm}$ less in comparison to implants without being statistically significant. Up to the 5-year follow-up, a mean loss of -0.07 to $-0.1 \mathrm{~mm} /$ year was recorded. The volume differences between implants and natural teeth amounted to $0.08( \pm 0.21) \mathrm{mm}$ (baseline to 1 year), $-0.30( \pm 0.47) \mathrm{mm}$ (baseline to 5 years) and $-0.20( \pm 0.35) \mathrm{mm}$ (1 year to 5 years). These data are comparable to the present study, revealing a yearly loss of $-0.1 \mathrm{~mm}$ in group RES and of $-0.12 \mathrm{~mm}$ in group N-RES.

The two study groups only differed in terms of the membrane used to perform GBR. At implant placement, the horizontal bone thickness amounted to $3.46 \mathrm{~mm}( \pm 0.52)$ (RES) and $2.82 \mathrm{~mm}( \pm 0.50)$ (N-RES) (Naenni, et al., 2017). Even though more soft tissue dehiscences had occurred in group RES, no membranes had to be prematurely removed. At 6 months, when reentry was performed in both groups conducting a full thickness flap in order to remove the membrane (N-RES group) and to measure the buccal contour (RES and N-RES). At this time-point bone was present on the buccal surface of all implants at all sites. Soft tissue dehiscences were not associated with an increased residual defect height, which is in line with a previous publication (Zitzmann et al. 1997). The horizontal bone loss, however, was significantly different in favor of group $\mathrm{N}$-RES $0.14 \mathrm{~mm}( \pm 0.79)$ (compared to group RES with $2.23 \mathrm{~mm}( \pm 1.21)$ ). In the present study, a new baseline at the time of crown insertion was defined to evaluate the longer-term stability of the peri-implant tissues and the buccal contour. Interestingly, up to FU-1, group N-RES (-0.14) showed less mean volume shrinkage compared to group RES $(-0.22)$. Up to 3 years, however, no significant differences were observed between the two groups (N-RES $(-0.32)$ and RES $(-0.30))$. These observations highlight 
that contour changes of the peri-implant tissues are ongoing even after crown insertion and that these remodeling processes may be influenced by the materials used for the GBR procedure. Similar observations were reported in a recent systematic reviews (Merli, et al., 2016).

Apart from linear and volumetric changes of the contour, the health of the peri-implant tissues as well as the comparison to natural control teeth over time are of importance. Median PD values were stable over time (FU1, FU-3) in both groups. The comparison of PD values between implants and control teeth, however, was significant at all time-points and in both, the resorbable and non-resorbable membrane group. At implant sites, the barrier epithelium with a dimension of $2 \mathrm{~mm}$ and a 1.3-1.8 $\mathrm{mm}$ zone of connective tissue define the biologic width (Berglundh, Lindhe, 1996), roughly measuring $3.8 \mathrm{~mm}$. For natural teeth, the dimension of the dentogingival unit is reported to be $2.7 \mathrm{~mm}$ (Gargiulo, Wentz, Orban, 1960; Vacek, Gher, Assad, Richardson, Giambarresi, 1994). Differences between implant sites and natural teeth were explained by the lack of Sharpey's fibres at implant sites, allowing the probe to penetrate closer to the bone crest (Berglundh, Lindhe, 1996). In a multi-level analysis of associated factors, tooth data from 601 healthy adults were retrospectively analyzed (Farina, Tomasi, Trombelli, 2013). An overall probability of $21 \%(0.21 ; 95 \%$ CI: $0.19-0.23)$ for sites to be BOP positive was detected. These findings are in accordance with the results of the study, demonstrating median BOP values of 30.5\% (RES), $32.1 \%$ (N-RES) and $13.7 \%$ for control teeth. The data thereby underline, that implant sites are associated with higher BOP values, without reaching substantial differences compared to control teeth.

\section{Conclusions}


Within the limits of this clinical study it can be concluded that, at 3 years of function, dental implants with simultaneously performed GBR using either a resorbable or non-resorbable membranes, result in:

- a minor (less than $0.4 \mathrm{~mm}$ in both groups), but ongoing loss of the buccal contour.

- a similar buccal contour at 1 year and similar contour changes up to 3 years.

-stable interproximal bone levels and healthy tissue using both membranes up to 3 years.

\section{Acknowledgements and conflict of interest}

This study was supported by a research grant from the Swiss Dental Association (SSO), Bern, Switzerland and by the Clinic of Fixed and Removable Prosthodontics and Dental Material Science, University of Zurich, Switzerland. Dental implants were provided by Dentsply-Sirona Implants, Mölndal, Sweden, however membranes and bone substitute materials by Geistlich Pharma AG, Wolhusen, Switzerland.

The authors would like to gratefully acknowledge Prof. Dr. Jürg Hüsler for his statistical assistance and Gisela Müller, study monitor at the Clinic for Fixed and Removable Prosthodontics and Dental Material Science, University of Zurich, Switzerland, for her support with the data and manuscript preparation. The investigators do not report any conflicts of interest related to this study.

\section{Figure legends}

Figure 1. Clinical Situation and corresponding volumetric outcome measures; Fig 1(a-c) example of N-RES group at (a) BL, (b) FU-1, (c) FU3); Fig 1(d-f) example of RES group at (d) BL, (e) FU-1, (f) FU-3; BL= baseline (yellow), FU-1=1-year follow-up (green), FU-3=3-year follow up (grey), RES= resorbable membrane, N-RES= titanium-reinforced nonresorbable membrane, $\mathrm{ROI}=$ region of interest (orange). 
Figure 2. (a) Cross-section of buccal contour in the N-RES group and (b) in the RES group. Differences of tissue thickness were analysed at 1 and 3 $\mathrm{mm}$ below the mucosal margin (scale). The differences between baseline (yellow), FU-1 (green) and FU-3 (grey) were measured. For volumetric measurements, the region of interest (ROI) (orange) was compared at different time-points ( $\mathrm{BL}, \mathrm{FU}-1, \mathrm{FU}-3) ; \mathrm{BL}=$ baseline, $\mathrm{FU}-1=1$-year followup, $\mathrm{FU}-3=3$-year follow up, RES= resorbable membrane, N-RES= titanium-reinforced non-resorbable membrane

Table 1. Descriptive data of two dimensional x-ray for interproximal marginal bone levels (MBLinterprox); $p$-values between the groups, $B L=$ baseline, FU-1= 1-year follow-up, FU-3=3-year follow up, RES= resorbable membrane, $\mathrm{N}-\mathrm{RES}=$ titanium-reinforced non-resorbable membrane

Table 2. Volumetric outcome measures; $M D 1=$ the calculated median volume changes at the buccal aspect between baseline and one year follow up, MD3= the calculated median volume changes at the buccal aspect between baseline and three year follow up, RES $=$ resorbable membrane, $\mathrm{N}$-RES $=$ titanium-reinforced non-resorbable membrane, $\mathrm{p}$ values between the groups

Table 3. Linear outcome measures; $T W=$ tissue width of the peri-implant contour at $1 \mathrm{~mm}$ (TW1) and at $3 \mathrm{~mm}$ (TW3) below the buccal mucosal margin; Differences $(\Delta)$ between the absolute ridge width at $1 \mathrm{~mm}$ ( $\Delta \mathrm{TW} 1$ ) and $3 \mathrm{~mm}(\triangle \mathrm{TW} 3) ; \mathrm{RES}=$ resorbable membrane; $\mathrm{N}-\mathrm{RES}=$ titaniumreinforced non-resorbable membrane; $\mathrm{p}$-values between the groups

Appendix 1. Clinical measurements; $B L=$ baseline, $F U-1=1$-year followup, $\mathrm{FU}-3=3$-year follow up, RES= resorbable membrane, N-RES= 
titanium-reinforced non-resorbable membrane, $\mathrm{PD}=$ probing depth, $\mathrm{BOP}=$ bleeding on probing, $\mathrm{PCR}=$ plaque control record

Appendix 2. Differences of clinical measurements between implant sites and control teeth; $\mathrm{BL}=$ baseline, FU-1= 1-year follow-up, $\mathrm{FU}-3=3$-year follow up, RES = resorbable membrane, N-RES = titanium-reinforced nonresorbable membrane, $\mathrm{PD}=$ probing depth, $\mathrm{BOP}=$ bleeding on probing, $\mathrm{PCR}=$ plaque control record

\section{References}

Ainamo, J. \& Bay, I. (1975). Problems and proposals for recording gingivitis and plaque. International Dental Journal 25: 229-235.

Benic, G. I. \& Hammerle, C. H. (2014). Horizontal bone augmentation by means of guided bone regeneration. Periodontology 2000 66: 13-40. doi:10.1111/prd.12039

Benic, G. I., Mokti, M., Chen, C. J., Weber, H. P., Hammerle, C. H. \& Gallucci, G. O. (2012). Dimensions of buccal bone and mucosa at immediately placed implants after 7 years: a clinical and cone beam computed tomography study. Clinical Oral Implants Research 23: 560566. doi:10.1111/j.1600-0501.2011.02253.x

Berglundh, T. \& Lindhe, J. (1996). Dimension of the periimplant mucosa. Biological width revisited. Journal of Clinical Periodontology 23: 971-973.

Bienz, S. P., Jung, R. E., Sapata, V. M., Hammerle, C. H. F., Husler, J. \& Thoma, D. S. (2017). Volumetric changes and peri-implant health at implant sites with or without soft tissue grafting in the esthetic zone, a retrospective case-control study with a 5-year follow-up. Clinical Oral Implants Research 28: 1459-1465. doi:10.1111/clr.13013

Buser, D., Chappuis, V., Bornstein, M. M., Wittneben, J. G., Frei, M. \& Belser, U. C. (2013). Long-term stability of contour augmentation with early implant placement following single tooth extraction in the esthetic zone: a prospective, cross-sectional study in 41 patients with a 5- to 9- 
year follow-up. Journal of Periodontology 84: 1517-1527. doi:10.1902/jop.2013.120635

Carpio, L., Loza, J., Lynch, S. \& Genco, R. (2000). Guided bone regeneration around endosseous implants with anorganic bovine bone mineral. A randomized controlled trial comparing bioabsorbable versus non-resorbable barriers. Journal of Periodontology 71: 1743-1749. doi:10.1902/jop.2000.71.11.1743

Chappuis, V., Araujo, M. G. \& Buser, D. (2017). Clinical relevance of dimensional bone and soft tissue alterations post-extraction in esthetic sites. Periodontology 2000 73: 73-83. doi:10.1111/prd.12167

Chen, S. T., Beagle, J., Jensen, S. S., Chiapasco, M. \& Darby, I. (2009). Consensus statements and recommended clinical procedures regarding surgical techniques. International Journal of Oral and Maxillofacial Implants 24 Suppl: 272-278.

Chen, S. T. \& Buser, D. (2014). Esthetic outcomes following immediate and early implant placement in the anterior maxilla--a systematic review. International Journal of Oral and Maxillofacial Implants 29 Suppl: 186215. doi:10.11607/jomi.2014suppl.g3.3

Dahlin, C., Linde, A., Gottlow, J. \& Nyman, S. (1988). Healing of bone defects by guided tissue regeneration. Plastic and Reconstructive Surgery 81: $672-676$.

Dahlin, C., Sennerby, L., Lekholm, U., Linde, A. \& Nyman, S. (1989). Generation of new bone around titanium implants using a membrane technique: an experimental study in rabbits. International Journal of Oral and Maxillofacial Implants 4: 19-25.

De Bruyckere, T., Eghbali, A., Younes, F., De Bruyn, H. \& Cosyn, J. (2015). Horizontal stability of connective tissue grafts at the buccal aspect of single implants: a 1-year prospective case series. Journal of Clinical Periodontology 42: 876-882. doi: $10.1111 /$ jcpe. 12448

Esposito, M., Grusovin, M. G., Felice, P., Karatzopoulos, G., Worthington, H. V. \& Coulthard, P. (2009). The efficacy of horizontal and vertical bone augmentation procedures for dental implants - a Cochrane systematic review. European Journal of Oral Implantology 2: 167-184. 
Esposito, M., Grusovin, M. G., Worthington, H. V. \& Coulthard, P. (2006). Interventions for replacing missing teeth: bone augmentation techniques for dental implant treatment. Cochrane Database Syst Rev: CD003607. doi: $10.1002 / 14651858 . C D 003607 . p u b 2$

Farina, R., Tomasi, C. \& Trombelli, L. (2013). The bleeding site: a multilevel analysis of associated factors. Journal of Clinical Periodontology 40: 735-742. doi: $10.1111 /$ jcpe. 12118

Gargiulo, A. W., Wentz, F. M. \& Orban, B. (1960). Dimensions and relations of the dentogingival junction in humans.

Hammerle, C. H., Bragger, U., Schmid, B. \& Lang, N. P. (1998).

Successful bone formation at immediate transmucosal implants: a clinical report. International Journal of Oral and Maxillofacial Implants 13: 522530.

Hjalmarsson, L., Gheisarifar, M. \& Jemt, T. (2016). A systematic review of survival of single implants as presented in longitudinal studies with a follow-up of at least 10 years. European Journal of Oral Implantology 9 Suppl 1: S155-162.

Jung, R. E., Herzog, M., Wolleb, K., Ramel, C. F., Thoma, D. S. \& Hammerle, C. H. (2017). A randomized controlled clinical trial comparing small buccal dehiscence defects around dental implants treated with guided bone regeneration or left for spontaneous healing. Clinical Oral Implants Research 28: 348-354. doi:10.1111/clr.12806

Kuchler, U., Chappuis, V., Gruber, R., Lang, N. P. \& Salvi, G. E. (2016). Immediate implant placement with simultaneous guided bone regeneration in the esthetic zone: 10-year clinical and radiographic outcomes. Clinical Oral Implants Research 27: 253-257. doi: $10.1111 / \mathrm{clr} .12586$

Lutz, R., Neukam, F. W., Simion, M. \& Schmitt, C. M. (2015). Long-term outcomes of bone augmentation on soft and hard-tissue stability: a systematic review. Clinical Oral Implants Research 26 Suppl 11: 103-122. doi: $10.1111 /$ clr.12635

Merheb, J., Vercruyssen, M., Coucke, W., Beckers, L., Teughels, W. \& Quirynen, M. (2017). The fate of buccal bone around dental implants. A 12-month postloading follow-up study. Clinical Oral Implants Research 28: 103-108. doi: $10.1111 / \mathrm{clr} .12767$ 
Merli, M., Merli, I., Raffaelli, E., Pagliaro, U., Nastri, L. \& Nieri, M. (2016). Bone augmentation at implant dehiscences and fenestrations. A systematic review of randomised controlled trials. European Journal of Oral Implantology 9: 11-32.

Miyamoto, Y. \& Obama, T. (2011). Dental cone beam computed tomography analyses of postoperative labial bone thickness in maxillary anterior implants: comparing immediate and delayed implant placement. International Journal of Periodontics and Restorative Dentistry 31: 215225.

Mombelli, A. \& Lang, N. P. (1994). Clinical parameters for the evaluation of dental implants. Periodontology 2000 4: 81-86.

Naenni, N., Schneider, D., Jung, R. E., Husler, J., Hammerle, C. H. F. \& Thoma, D. S. (2017). Randomized clinical study assessing two membranes for guided bone regeneration of peri-implant bone defects: clinical and histological outcomes at 6 months. Clinical Oral Implants Research 28: 1309-1317. doi:10.1111/clr.12977

O'Leary, T. J., Drake, R. B. \& Naylor, J. E. (1972). The plaque control record. Journal of Periodontology 43: 38. doi:10.1902/jop.1972.43.1.38

Ramfjord, S. P. (1974). Indexes for Measurement of Loss of Periodontium. Journal of Periodontal Research: 78-88.

Sanz Martin, I., Benic, G. I., Hammerle, C. H. \& Thoma, D. S. (2016). Prospective randomized controlled clinical study comparing two dental implant types: volumetric soft tissue changes at 1 year of loading. Clinical Oral Implants Research 27: 406-411. doi:10.1111/clr.12579

Sapata, V. M., Sanz-Martin, I., Hammerle, C. H., César-Neto, J. B., Jung, R. E. \& Thoma, D. S. Volumetric changes of peri-implant tissues over 5 years: a randomized controlled trial comparing a one- and two-piece implant system. Clinical Oral Implants Research submitted.

Schneider, D., Grunder, U., Ender, A., Hammerle, C. H. \& Jung, R. E. (2011). Volume gain and stability of peri-implant tissue following bone and soft tissue augmentation: 1-year results from a prospective cohort study. Clinical Oral Implants Research 22: 28-37. doi:10.1111/j.16000501.2010.01987.x 
Schneider, D., Weber, F. E., Grunder, U., Andreoni, C., Burkhardt, R. \& Jung, R. E. (2014). A randomized controlled clinical multicenter trial comparing the clinical and histological performance of a new, modified polylactide-co-glycolide acid membrane to an expanded polytetrafluorethylene membrane in guided bone regeneration procedures. Clinical Oral Implants Research 25: 150-158. doi:10.1111/clr.12132

Sicilia, A., Quirynen, M., Fontolliet, A., Francisco, H., Friedman, A., Linkevicius, T., Lutz, R., Meijer, H. J., Rompen, E., Rotundo, R., Schwarz, F., Simion, M., Teughels, W., Wennerberg, A. \& Zuhr, O. (2015). Longterm stability of peri-implant tissues after bone or soft tissue augmentation. Effect of zirconia or titanium abutments on peri-implant soft tissues. Summary and consensus statements. The 4th EAO Consensus Conference 2015. Clinical Oral Implants Research 26 Suppl 11: 148-152. doi: $10.1111 /$ clr.12676

Thoma, D. S., Jung, R. E., Schneider, D., Cochran, D. L., Ender, A., Jones, A. A., Gorlach, C., Uebersax, L., Graf-Hausner, U. \& Hammerle, C. H. (2010). Soft tissue volume augmentation by the use of collagen-based matrices: a volumetric analysis. Journal of Clinical Periodontology 37: 659-666. doi:10.1111/j.1600-051X.2010.01581.x

Vacek, J. S., Gher, M. E., Assad, D. A., Richardson, A. C. \& Giambarresi, L. I. (1994). The dimensions of the human dentogingival junction. International Journal of Periodontics and Restorative Dentistry 14: 154165.

Zitzmann, N. U., Naef, R. \& Scharer, P. (1997). Resorbable versus nonresorbable membranes in combination with Bio-Oss for guided bone regeneration. International Journal of Oral and Maxillofacial Implants 12: 844-852. 

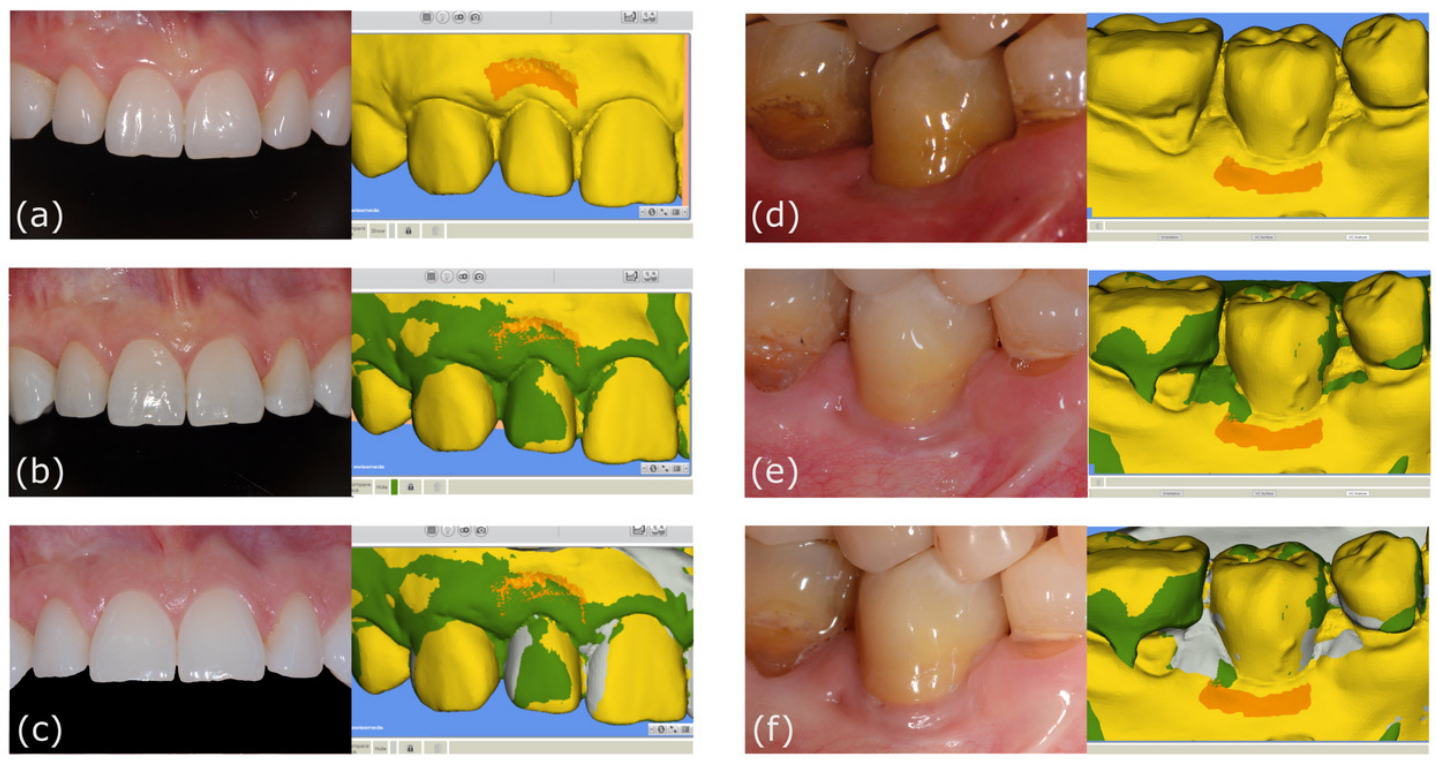

Figure 1
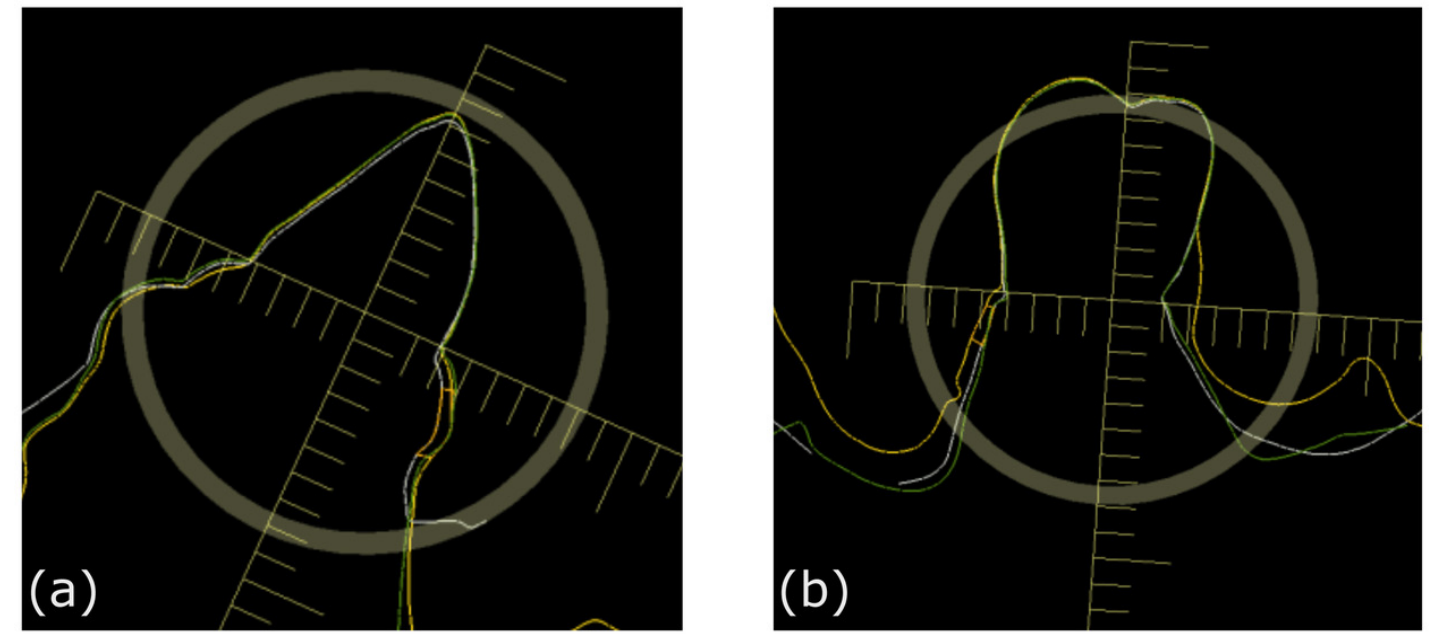

Figure 2 
Table 1:

\begin{tabular}{|c|c|c|c|c|c|c|c|}
\hline & \multicolumn{3}{|c|}{ RES } & \multicolumn{3}{|c|}{ N-RES } & \multirow{2}{*}{$\begin{array}{c}\mathrm{p}- \\
\text { value }\end{array}$} \\
\hline & Mean \pm SD & Median & Q1 ; Q3 & Mean \pm SD & Median & Q1 ; Q3 & \\
\hline $\mathrm{BL}$ & $0.23 \pm 0.49$ & 0.11 & $-0.07 ; 0.46$ & $0.12 \pm 0.09$ & 0.14 & $0.06 ; 0.19$ & 0.654 \\
\hline FU-1 & $0.23 \pm 0.19$ & 0.23 & $0.10 ; 0.41$ & $0.10 \pm 0.17$ & 0.13 & $-0.02 ; 0.23$ & 0.156 \\
\hline FU-3 & $0.19 \pm 0.21$ & 0.26 & $0.04 ; 0.36$ & $0.16 \pm 0.10$ & 0.14 & $0.08 ; 0.20$ & 0.500 \\
\hline
\end{tabular}

Table 2:

\begin{tabular}{|c|c|c|c|c|c|c|c|c|c|}
\hline & \multicolumn{4}{|c|}{ RES } & \multicolumn{4}{|c|}{ N-RES } & \multirow[t]{2}{*}{ p-value } \\
\hline & Mean \pm SD & Median & Q1; Q3 & p-value & Mean \pm SD & Median & Q1; Q3 & p-value & \\
\hline MD1 & $-0.22 \pm 0.21$ & -0.19 & $-0.31 ;-0.06$ & 0.0020 & $-0.14 \pm 0.30$ & -0.12 & $-0.37 ; 0.04$ & 0.1855 & 0.5923 \\
\hline MD3 & $-0.30 \pm 0.25$ & -0.31 & $-0.45 \pm-0.07$ & 0.0039 & $-0.32 \pm 0.22$ & -0.38 & $-0.40 ;-0.14$ & 0.0078 & 0.6685 \\
\hline
\end{tabular}


Table 3:

\begin{tabular}{|c|c|c|c|c|c|c|c|c|c|c|}
\hline & & \multicolumn{4}{|c|}{ RES } & \multicolumn{4}{|c|}{ N-RES } & \multirow[t]{2}{*}{ p-value } \\
\hline & & Mean \pm SD & Median & Q1; Q3 & p-value & Mean \pm SD & Median & Q1; Q3 & p-value & \\
\hline \multirow[t]{2}{*}{ TW1 } & $\Delta T W 1$ & $-0.28 \pm 0.29$ & -0.24 & $-0.42 ;-0.13$ & 0.0068 & $-0.28 \pm 0.23$ & -0.29 & $-0.42 ;-0.13$ & 0.0195 & 0.7804 \\
\hline & $\Delta T W 3$ & $-0.41 \pm 0.38$ & -0.33 & $-0.48 ;-0.15$ & 0.0010 & $-0.37 \pm 0.14$ & -0.38 & $-0.44 ;-0.31$ & 0.0039 & 0.7804 \\
\hline \multirow[t]{2}{*}{ TW3 } & $\Delta \mathrm{TW}_{1}$ & $-0.37 \pm 0.42$ & -0.36 & $-0.77 ;-0.09$ & 0.0244 & $-0.37 \pm 0.29$ & -0.24 & $-0.53 ;-0.17$ & 0.0039 & 0.9571 \\
\hline & $\Delta T W 3$ & $-0.56 \pm 0.33$ & -0.49 & $-0.89 ;-0.22$ & 0.0010 & $-0.59 \pm 0.30$ & -0.60 & $-0.84 ;-0.30$ & 0.0039 & 0.7525 \\
\hline
\end{tabular}




\section{Appendix 1:}

\begin{tabular}{|c|l|l|l|c|c|c|c|}
\cline { 3 - 9 } \multicolumn{2}{c|}{} & \multicolumn{4}{c|}{ RES } & \multicolumn{3}{c|}{ N-RES } \\
\cline { 3 - 9 } \multicolumn{2}{c|}{} & Mean \pm SD & Median & Q1; Q3 & Mean \pm SD & Median & Q1; Q3 \\
\hline \multirow{3}{*}{ PD } & BL & $3.18 \pm 1.08$ & 3.17 & $2.67 ; 3.42$ & $3.11 \pm 0.67$ & 3.00 & $2.67 ; 3.67$ \\
\cline { 2 - 9 } & FU-1 & $3.23 \pm 0.89$ & 3.00 & $2.83 ; 3.33$ & $3.19 \pm 0.64$ & 3.00 & $2.83 ; 3.50$ \\
\cline { 2 - 9 } & FU-3 & $3.26 \pm 0.86$ & 3.17 & $2.50 ; 4.17$ & $3.39 \pm 0.49$ & 3.33 & $3.17 ; 3.69$ \\
\hline \multirow{3}{*}{ BOP } & BL & $0.28 \pm 0.27$ & 0.17 & $0.08 ; 0.42$ & $0.26 \pm 0.30$ & 0.17 & $0.17 ; 0.33$ \\
\cline { 2 - 9 } & FU-1 & $0.33 \pm 0.27$ & 0.33 & $0.00 ; 0.67$ & $0.22 \pm 0.12$ & 0.17 & $0.17 ; 0.33$ \\
\cline { 2 - 9 } & FU-3 & $0.30 \pm 0.21$ & 0.33 & $0.17 ; 0.50$ & $0.48 \pm 0.27$ & 0.33 & $0.33 ; 0.50$ \\
\hline \multirow{3}{*}{ PCR } & BL & $0.11 \pm 0.16$ & 0.00 & $0.00 ; 0.17$ & $0.07 \pm 0.17$ & 0.00 & $0.00 ; 0.50$ \\
\cline { 2 - 9 } & FU-1 & $0.05 \pm 0.08$ & 0.00 & $0.00 ; 0.17$ & $0.11 \pm 0.14$ & 0.00 & $0.00 ; 0.17$ \\
\cline { 2 - 9 } & FU-3 & $0.11 \pm 0.20$ & 0.00 & $0.00 ; 0.17$ & $0.06 \pm 0.12$ & 0.00 & $0.00 ; 0.33$ \\
\hline
\end{tabular}




\section{Appendix 2:}

\begin{tabular}{|c|c|c|c|c|c|c|c|c|c|}
\cline { 3 - 10 } \multicolumn{2}{c|}{} & \multicolumn{4}{c|}{ RES / Control } & \multicolumn{4}{c|}{ N-RES / Control } \\
\cline { 3 - 10 } \multicolumn{2}{c|}{} & Mean \pm SD & Median & Q1; Q3 & p-value & Mean \pm SD & Median & Q1; Q3 & p-value \\
\hline \multirow{3}{*}{ PD } & BL & $0.73 \pm 1.15$ & 0.67 & $0.21 ; 0.88$ & 0.017 & $0.60 \pm 0.59$ & 0.50 & $0.17 ; 1.08$ & 0.031 \\
\cline { 2 - 10 } & FU-1 & $0.78 \pm 0.80$ & 0.58 & $0.33 ; 1.33$ & 0.006 & $0.66 \pm 0.635$ & 0.58 & $0.17 ; 1.00$ & 0.020 \\
\cline { 2 - 10 } & FU-3 & $0.74 \pm 0.72$ & 0.75 & $0.25 ; 1.17$ & 0.007 & $0.91 \pm 0.43$ & 0.83 & $0.75 ; 1.17$ & 0.004 \\
\hline \multirow{3}{*}{ BOP } & BL & $0.28 \pm 0.27$ & 0.17 & $0.08 ; 0.42$ & 0.969 & $0.15 \pm 0.34$ & 0.08 & $-0.08 ; 0.17$ & 0.383 \\
\cline { 2 - 10 } & FU-1 & $0.33 \pm 0.27$ & 0.33 & $0.00 ; 0.67$ & 0.127 & $0.14 \pm 0.13$ & 0.17 & $0.08 ; 0.17$ & 0.023 \\
\cline { 2 - 10 } & FU-3 & $0.31 \pm 0.21$ & 0.33 & $0.17 ; 0.50$ & 0.068 & $0.30 \pm 0.24$ & 0.25 & $0.17 ; 0.42$ & 0.008 \\
\hline \multirow{3}{*}{ PCR } & BL & $-0.08 \pm 0.12$ & -0.13 & $-0.17 ; 0.00$ & 0.033 & $-0.22 \pm 0.18$ & -0.25 & $-0.33 ;-0.08$ & 0.016 \\
\cline { 2 - 10 } & FU-1 & $-0.11 \pm 0.11$ & -0.08 & $-0.17 ;-0.00$ & 0.016 & $-0.05 \pm 0.20$ & 0.00 & $-0.08 ; 0.08$ & 0.656 \\
\cline { 2 - 10 } & FU-3 $-0.10 \pm 0.24$ & -0.08 & $-0.25 ; 0.00$ & 0.25 & $-0.14 \pm 0.20$ & -0.08 & $-0.17 ; 0.00$ & 0.063 \\
\hline
\end{tabular}

